\title{
On the relationship between reading, listening, and speaking: It's different for people's names
}

\author{
TIM VALENTINE and JARROD HOLLIS \\ Goldsmiths College, University of London, London, England \\ and \\ VIV MOORE \\ University of Durham, Durham, England
}

\begin{abstract}
Two experiments are reported that tested predictions derived from the framework of face, object, and word recognition proposed by Valentine, Brennen, and Brédart (1996). The findings were as follows: (1) Production of a celebrity's name in response to seeing the celebrity's face primed a subsequent familiarity decision to the celebrity's printed name. The degree of repetition priming observed was as great as that observed when a familiarity decision to the printed name was repeated in the prime and test phases of the experiment. (2) Making a familiarity decision to an auditory presentation of a celebrity's name primed a familiarity decision to the same celebrity's name presented visually. The magnitude of cross-modality priming was as great as the magnitude of within-modality repetition priming. This result for people's names contrasted with the effects observed in lexical decision tasks, in which no reliable cross-modality priming was observed. The results cannot be accounted for by previous models of face and name processing. They show a marked contrast between processing people's names and processing words. The results support the framework proposed by Valentine et al. (1996). The implications for models of speech production, perception, and reading are discussed, together with the potential of the methodology to elucidate our understanding of proper name processing.
\end{abstract}

Models of face recognition have been developed by analogy to models of visual word recognition. Hay and Young (1982) and Bruce and Young (1986) explicitly derived the notion of a face recognition unit, which was postulated to mediate recognition of a familiar face, by analogy to Morton's (1979) logogen model of word recognition. A logogen is an entry in a mental lexicon that represents a specific known word. The logogen model included a single stage of lexical access for speech production (output logogens) that was separate from modality-specific representations for word recognition (input logogens). The assumption of separate lexical representations for recognition and production of words is typical of current models of word recognition (see, e.g., Ellis \& Young, 1988; Seidenberg, 1988). As a result of the analogy with visual word recognition, it has been assumed that production of people's names involves a single stage of access to a phonological representation that is separate from the representations required to recognize a printed or written name (see, e.g., Burton, Bruce, \& Johnston, 1990; Valentine, Brédart, Lawson, \& Ward, 1991).

In contrast, models of speech production assume that lexical access involves two stages. The message to be articulated is formulated in a nonlexical conceptual system.

This research was supported by a grant from the Economic and Social Research Council (Grant R000234612). Correspondence should be addressed to T. Valentine, Department of Psychology, Goldsmiths College, University of London, New Cross, London SE14 6NW, England (e-mail: t.valentine@gold.ac.uk).

-Accepted by previous editor, Geoffrey R. Loftus
The first stage of lexical access involves access to a lexical entry that specifies the lexical item, its syntactic class, and its style of use, but not its phonological form. The phonology of the lexical item or word form is accessed subsequently. Most current models of speech production include two stages of lexical access (Dell, 1986; Garrett, 1975, 1980; Levelt, 1989). The view that lexical access involves two stages is so commonly held that the current debate in the speech production literature concerns whether semantic and phonological representations are activated in a strict sequence or whether activation can flow interactively between the semantic and phonological representations.

Brédart and Valentine (1992) pointed out that naming a familiar face is an act of speech production. It would be surprising if naming a face involved a different process of lexical access from that involved in speech production. They showed that the pattern of semantic and phonological errors that occurred in a face naming task was the same as that observed in an analogous object naming task. Therefore, Brédart and Valentine proposed that models of face naming (see, e.g., Bruce \& Young, 1986) need to be modified to include two stages of lexical access.

Valentine, Brennen, and Brédart (1996) outlined a comprehensive framework that aimed to make explicit the relationship between face recognition, word recognition, and object recognition in a model that takes account of current models of speech production. This enterprise required them to address the relationship between input and output processes. Valentine et al. (1996) followed the 
model outlined by Roelofs (1992) by proposing that there is a single semantic lexicon that mediates both lexical access in speech production and identification of lexical entries from their word forms, but that the phonological output lexicon is separate from the phonological input lexicon. Visual word forms are assumed to be separately represented in an orthographic input lexicon. The framework proposed is shown in Figure 1. A detailed discussion of the framework and its development can be found in Valentine et al. (1996).

In the domain of auditory word recognition and speech production, the issue of whether input and output repre-

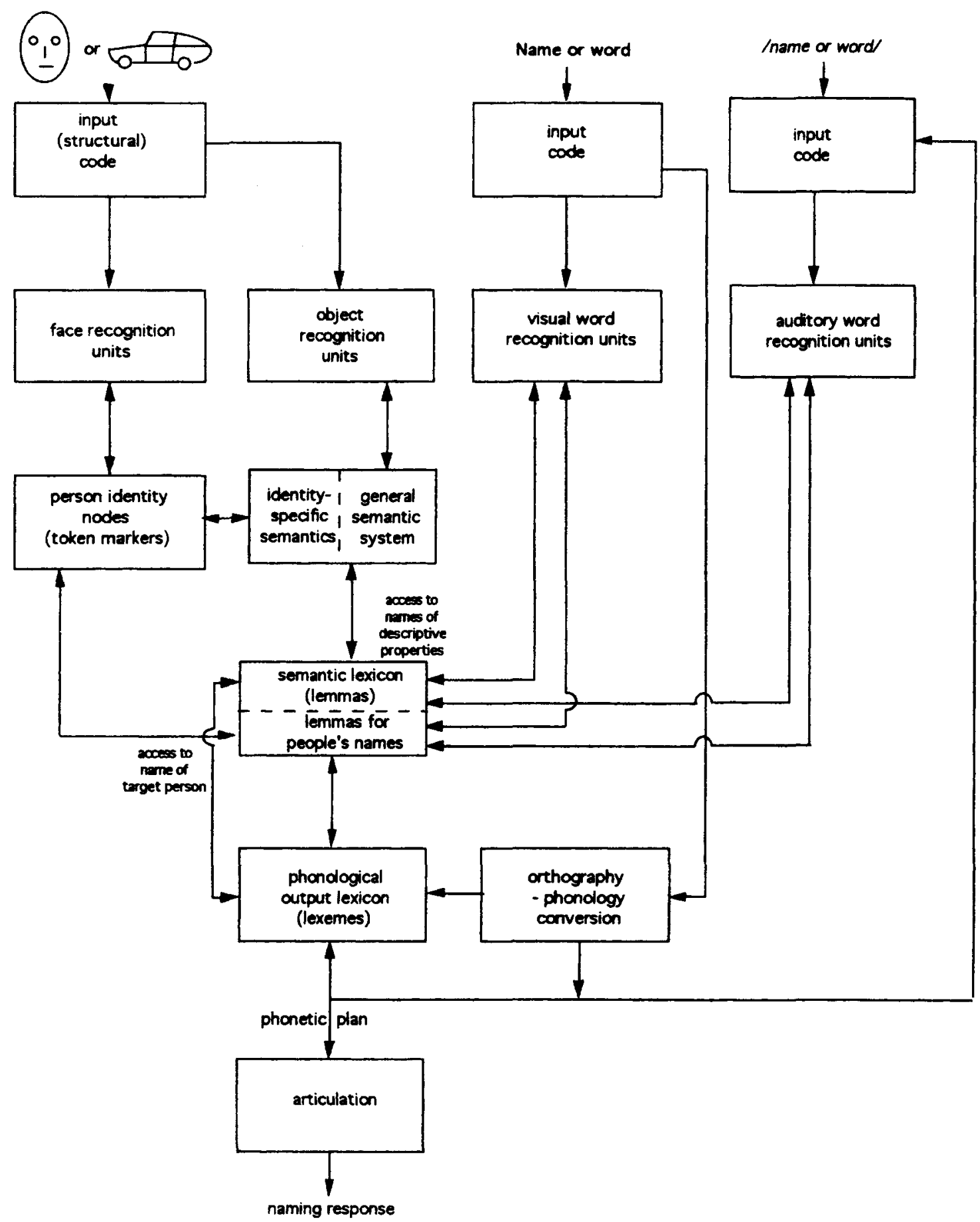

Figure 1. A functional model of face, name, word, and object recognition. From The Cognitive Psychology of Proper Names: On the Importance of Being Ernest, p. 172, by T. Valentine, T. Brennen, and S. Brédart, 1996, London: Routledge. Copyright 1996 by Routledge. Reprinted with permission. 
sentations are shared or separate is unresolved. However, the existence of a common semantic lexicon and separate phonological lexicons is broadly consistent with the available data (see Monsell, 1987, ${ }^{1}$ and Shallice, 1988, for reviews.)

It is possible to derive two predictions from the framework shown in Figure 1 that differ from those derived from earlier models of face and name processing (e.g., Burton et al., 1990; Valentine et al., 1991). Both predictions depend upon the role of the person identity nodes (PINs) in mediating recognition of people's faces and names, or, more specifically, on the strengthening of the link between a PIN and the corresponding lemma for the person's name that results from retrieval or recognition of a person's name.

One prediction is that producing a person's name in response to seeing his/her face should prime recognition of his/her name; the second prediction is that repetition priming of familiarity decisions to people's names should cross input modality. (That is, having decided that a heard name of a celebrity is familiar should prime a subsequent decision that a written version of the same celebrity's name is familiar.) The former prediction was tested in Experiment 1 and the latter was tested in Experiment 2. For each prediction, we describe how the prediction is derived from the framework and what prediction would be derived from earlier models of face and name recognition. We also consider whether the prediction would be expected to hold for analogous word recognition and production tasks and review the relevant evidence.

Three processing assumptions underlie the predictions made: (1) It is assumed that familiarity decisions about people's names and faces are based on the activation of PINs passing a threshold. This follows assumptions made by Burton et al. (1990) from an implementation of face processing models using an interactive activation and competition architecture. Similarly, it is assumed that lexical decisions are based on the activation of lemmas (units in the semantic lexicon). It should be noted that both assumptions require that the relevant decision is made on the basis of activation of the node or unit that is connected directly to nonlinguistic semantic representations. PINs have the role of "token markers" via which information about specific individuals is accessed. Token markers distinguish the cognitive processing of proper names and common names (see Valentine et al., 1996). Thus lemmas for common names access semantic memory directly, but lemmas for people's names access semantic memory only via PINs. (2) Repetition priming is the facilitation of processing a stimulus that results from a prior processing episode of the same stimulus. It is assumed that repetition priming results from a strengthening of a connection between units at different levels in the framework. The interpretation of repetition priming as a strengthening of connections was proposed by Burton et al. (1990); Monsell, Matthews, and Miller (1992); and Vitkovitch and Humphreys (1991). (3) It is assumed that links are bidirectional and that a single weight de- termines the strength of connectivity in both directions. This assumption has been made in interactive activation models of face and name processing (Brédart, Valentine, Calder, \& Gassi, 1995; Burton et al., 1990).

\section{Repetition Priming Between Name Production and Name Recognition}

If a subject sees the face of a celebrity and names it, according to the framework shown in Figure 1, the input code would activate the appropriate face recognition unit. The corresponding PIN would become activated and pass activation on to the appropriate lemma for the celebrity's name, before the phonology of the name is retrieved and passed for articulation. If subsequently the subject is required to decide whether the printed name of the celebrity is familiar, a different input is activated. The appropriate visual word recognition unit will become active and will in turn activate a matching lemma for the celebrity's name. Since a familiarity decision for a person's name must be based on activation of the PIN, activation must flow to the appropriate person identity node and activate it above threshold before a familiarity decision can be made.

The only processing stages that naming a celebrity's face and making a familiarity decision to his/her written name have in common is activation of the PIN - activation spreading along the PIN-lemma link and activation of the lemma for the celebrity's name. The flow of activation is in the opposite direction in the two tasks. If it is assumed that prior activation of a link results in a strengthening of connectivity, and that the strength of the connection is the same in both directions, it would be predicted that naming a celebrity's face would produce an effect of repetition priming on a subsequent familiarity decision to his/her name. The strengthened lemma-PIN link would lead to a faster rise in activation at the PIN than would be the case if the name familiarity decision was unprimed. Under these processing assumptions, there is no reason why the degree of priming from naming a face should be any less than that which would be observed if a name familiarity decision to the same name was repeated. Repeating the same task between the prime and test phase would prime links between earlier stages, whereas a face naming task would prime only the PINlemma link. However, effects at different levels in an interactive activation model are not additive. Therefore, it is possible that priming at the final level of processing may obscure any effects at earlier stages, especially if the unprimed access to that final stage is particularly slow or difficult.

It should be noted that the framework predicts a priming effect only from face naming. If the prime task involved a familiarity decision to a famous face, no effect of priming would be predicted. A familiarity decision to a face could be made on the basis of the activity of the PIN. There would be no requirement for the lemma for the celebrity's name to be activated to perform the task. If the processing during the prime phase was carried out only as far as the PIN, no priming effect would be pre- 
dicted because the weight of the PIN-lemma link would not have been strengthened during the prime phase.

It can be concluded that the framework shown in Figure 1 predicts an effect of repetition priming between production and recognition of people's names. Could this prediction have been derived from previous models of face and name recognition? The models of face and name recognition described by Burton et al. (1990) and Valentine et al. (1991) assume that recognition of names is mediated by a set of units (name recognition units) analogous to face recognition units, which access PINs directly and serve only to mediate recognition of familiar names. The only processing stage that naming a face and recognizing a name have in common is activation of the appropriate PIN. Since there are no links in common, and it is assumed that repetition priming arises from a strengthening of links, there is no mechanism from which these models can predict repetition priming.

The framework shown in Figure 1 predicts repetition priming of recognition of a celebrity's name from naming his/her face. But it does not predict the analogous priming of recognition of an object's name from having previously named the object. Object naming proceeds via object recognition units and activation of semantic information to activate the appropriate lemma. Recognition of an object name is based on activation of the lemma from the appropriate word recognition unit (or logogen). Since there are no links shared by the processing required by the two tasks, there is no mechanism for repetition priming. If the test task requires activation of semantic information, repetition priming would be found. Object naming can proceed only via the semantic system. In this case the links between semantic information and the lemma would be activated in object naming and in the test task and so could provide a locus for repetition priming. We discuss this issue in more detail in relation to Experiment 2.

The experimental literature shows that naming an object does not prime recognition of the object's name. Indeed, this result was one of the experimental findings that led Morton (1979) to distinguish output logogens from input logogens. Winnick and Daniel (1970) showed that producing an object name in naming a picture or in responding to a definition did not decrease the exposure duration required for subjects to subsequently identify the printed name of the object. Scarborough, Gerard, and Cortese (1979) found that naming an object did not prime a subsequent lexical decision to the printed name of the object.

The aim of Experiment 1 was to test the prediction that naming a celebrity's face will prime a subsequent familiarity decision to his/her name. The experiment had two phases, a prime phase and a test phase. The test phase was the same for all subjects and required subjects to decide whether a name presented on a computer screen was familiar or not. In the prime phase, there were three different conditions; each subject took part in only one of the prime tasks. In one condition, the prime task was the same as the test task - a name familiarity decision task. This condition was included to provide a baseline of the maximum effect of priming that would be observed in the test task. Since both the stimuli and the processing of primed items would be identical in both the prime and test phases, the conditions would maximize any facilitation from prior processing due to transfer-appropriate training or perceptual fluency. A set of 15 famous names was included in both the prime and test phases. These items formed the set of primed items. It was predicted that reaction times (RTs) of correct decisions to the primed items would be faster than RTs to unprimed items. In the second prime condition, subjects named famous faces in the prime task. It was predicted that the effect of priming in the test task resulting from this prime task would be as great as that observed from the name familiarity decision prime task. The third prime condition required subjects to make familiarity decisions to faces. This condition was included to establish whether it was necessary for faces to be named during the prime phase for a priming effect to be observed.

\section{EXPERIMENT 1}

\section{Method}

Subjects. Sixty volunteers took part in the experiment.

Stimuli. The experimental stimuli consisted of photographs of 90 celebrities, names of 55 of these celebrities, 80 photographs of unfamiliar people, and 40 unfamiliar names. (All of the stimuli used for the experimental trials are listed in Appendix A.) Sufficient additional stimuli to provide 10 practice trials for each prime task and the test task were also obtained. The photographs of faces were monochrome images of $256 \times 256$ pixels in 16 gray levels displayed at a screen resolution of $640 \times 480$ pixels. The celebrities selected were famous people from the following categories: television personalities (35), film stars (29), pop stars (7), sports personalities (7), politicians (10), and businesspeople (2). They were selected by one of the experimenters on the basis of their familiarity to students. The most familiar celebrities were chosen, within the constraint of the availability of a good quality photograph. Photographs were from a collection of pictures taken from magazines or stills from television programs. Photographs of unfamiliar faces were unknown people collected from the same sources (c.g., models from magazine advertisements). This ensured that the quality and style of photographs of familiar and unfamiliar people were similar.

Apparatus. The stimuli for all tasks were presented on the screen of a PC. The subjects' response was logged by using keypresses on the keyboard. The experiment was programmed using Micro Experimental Laboratory software (Schneider, 1988). RT was recorded with millisecond accuracy.

Design. The experiment consisted of two phases, a prime phase and a test phase. It had a mixed design with two factors: prime task (face naming, face familiarity decision, and name familiarity decision) and priming (primed vs. unprimed items). Each subject took part in one of three prime tasks, and each prime task was carried out by 20 subjects. Therefore, prime task was a between-subjects factor. The effect of priming was a within-subjects factor. There were two sets of 15 critical items. One set was included in both the prime and test phases. Responses to these items formed the data from "primed" items. The other set of 15 critical items appeared only in the test phase. Responses to these items formed the data from "un- 
primed" items. The assignment of items to the primed and unprimed conditions was counterbalanced across subjects for each prime task.

All subjects took part in an identical test phase. They made familiarity decisions to names (first and surnames) presented on the PC screen. Half were famous names and half were unfamiliar names. The dependent variables were the mean latency of correct responses to "critical" famous names and the accuracy of responses to these items during the test phase.

Procedure. The following details applied to all tasks (three prime tasks and the test task). Each task commenced with 10 practice items. Each trial consisted of a $250-\mathrm{msec}$ tone followed after $500 \mathrm{msec}$ by presentation of the stimulus. With the exception of the 15 primed items, no other items were repeated between prime and test tasks (including practice items). In all prime tasks, the faces or names of the same celebrities were included as stimuli.

In the face naming prime task, a picture of a celebrity was presented in each trial. The subject's task was to name the celebrity aloud. If necessary, the experimenter cued the subject with the celebrity's first name. However, the first name cue rarely elicited the full name from the subject. Therefore, in most cases, data from these items collected during the test phase were excluded from the data analysis (see below). The experimenter coded the subject's naming as accurate or inaccurate by making a keypress on the computer keyboard. The stimulus remained on the screen until the experimenter entered a keypress. Seventy-five photographs of celebrities were presented. The names of 15 of these celebrities were included in the test task.

The procedure for the face familiarity decision prime task was the same as the face naming task except for the following details. Faces of 40 celebrities and 40 unfamiliar faces were presented. Subjects were instructed to decide whether each face was familiar to them or not. They made their responses by pressing a "yes" or a "no" key on the keyboard. Subjects were instructed to respond as quickly and as accurately as possible. The subject's response terminated display of the stimulus.

The procedure was identical for the name familiarity decision prime task and the test task. In each trial, a full name was presented in the center of the screen. The subjects were instructed to decide whether each name was familiar to them or not. They made their responses by pressing a "yes" or a "no" key on the keyboard. Subjects were instructed to respond as quickly and as accurately as possible. The subject's response terminated display of the stimulus. Names of 40 celebrities and 40 unfamiliar names were presented in both the name familiarity decision prime task and the test task. (The only items repeated between the tasks were the 15 primed items.)

\section{Results}

Responses to the 15 critical primed and unprimed items during the test phase were subjected to analysis. A response was included in the analyses only if the correct response was given in both the prime phase and the test phase. Data from $7.3 \%$ of the critical items in the test phase were excluded from analysis because of errors made in either phase. Response accuracy is shown in Table 1 as a function of prime task and priming condition. The error rate to primed items was higher than to unprimed items because a primed item was counted as an error unless a correct response was made in both the prime and the test phases but only a correct response in the test phase was necessary for an unprimed item. This effect is particularly marked when the prime task is face naming because naming celebrities' faces out of context is a notoriously difficult task. No further analysis of accuracy data or of responses made during the prime phase was carried out.

Mean RT of correct responses to critical items in the test phase are plotted in Figure 2. In panel A, the mean for each experimental condition is plotted. The effect of priming is illustrated in panel $\mathrm{B}$, in which the difference between RT to unprimed and primed items is plotted. The error bars indicate the appropriate $95 \%$ confidence intervals from the subjects and items analyses reported below. The data illustrated in panel A were subjected to a $3 \times 2$ split-plot analysis of variance (ANOVA), taking subjects as the random factor (identified below with the suffix 1) and to an ANOVA with repeated measures on both factors, taking items as the random factor (identified below by the suffix 2 ).

The main effect of prime task was significant $\left[F_{1}(2,57)\right.$ $=4.03, M S_{\mathrm{e}}=35,544.54, p<.025 ; F_{2}(2,58)=70.66$, $\left.M S_{\mathrm{e}}=3,348.34, p<.0001\right]$. Mean RT following face naming prime task was $771 \mathrm{msec}$; RT following face familiarity decision prime task was 794 msec; RT following name familiarity decision prime task was $681 \mathrm{msec}$. Newman-Keuls pairwise comparisons revealed that RT in the test task following a name familiarity decision task in the prime phase was significantly faster than RT following the prime tasks in which faces were presented $\left(p_{1}<.05, p_{2}<.01\right)$. This result reflects a task practice effect. Carrying out the same task during the prime and test phases of the experiment speeded RT to all items in the test phase (primed and unprimed items). Further Newman-Keuls pairwise comparisons on items analysis data also revealed that RTs in the test phase were significantly faster following face naming than they were following face familiarity decision $\left(p_{2}<.05\right)$. This effect (which was not significant in the subjects analysis in which prime task was a between-subjects factor) was modified

Table 1

Mean Number of Errors Per Subject in Experiment 1 (Maximum $=15$ ) as a Function of Prime Task and Prime Condition

\begin{tabular}{|c|c|c|c|c|c|c|c|c|c|c|c|c|c|c|c|c|}
\hline \multirow{2}{*}{$\begin{array}{l}\text { Prime } \\
\text { Modality }\end{array}$} & \multicolumn{4}{|c|}{ Face Naming } & \multicolumn{4}{|c|}{$\begin{array}{c}\text { Face Familiarity } \\
\text { Decision }\end{array}$} & \multicolumn{4}{|c|}{$\begin{array}{c}\text { Name Familiarity } \\
\text { Decision }\end{array}$} & \multicolumn{4}{|c|}{ Mean } \\
\hline & $M$ & $\%$ & $S D$ & $\%$ & $M$ & $\%$ & $S D$ & $\%$ & $M$ & $\%$ & $S D$ & $\%$ & $M$ & $\%$ & $S D$ & $\%$ \\
\hline Primed & 2.25 & 15.00 & 1.97 & 13.13 & 1.35 & 9.00 & 2.03 & 13.53 & 1.15 & 7.67 & 0.93 & 6.20 & 1.58 & 10.53 & 1.79 & 11.93 \\
\hline Unprimed & 0.55 & 3.67 & 0.76 & 5.07 & 0.40 & 2.67 & 0.82 & 5.47 & 0.85 & 5.67 & 0.93 & 0.62 & 0.60 & 4.00 & 0.85 & 5.67 \\
\hline Mean & 1.40 & 9.33 & 1.71 & 11.40 & 0.87 & 5.80 & 1.60 & 10.67 & 1.00 & 6.67 & 0.93 & 6.20 & & & & \\
\hline
\end{tabular}

Note-Error rates for primed stimuli include trials on which an error was made in either the prime phase or the test phase. 
(A)

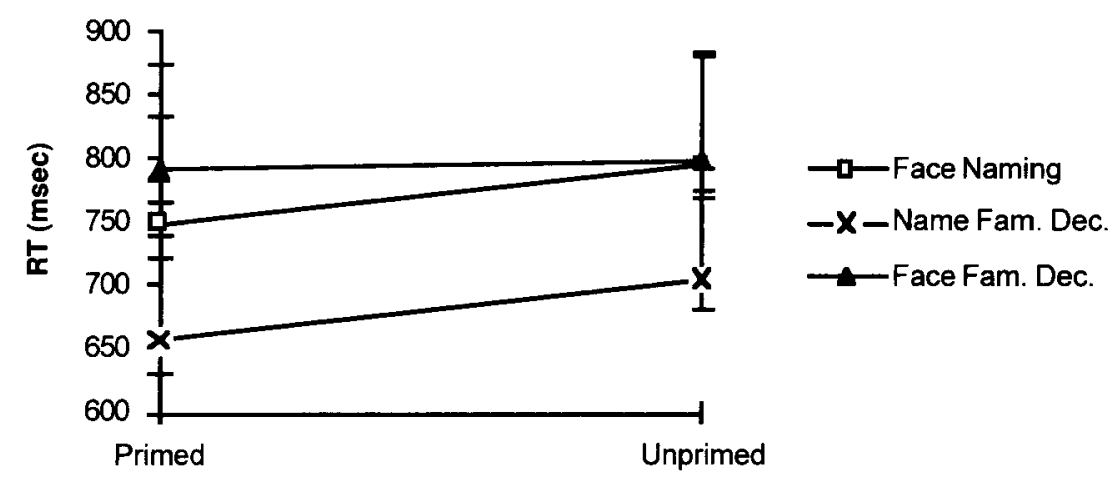

(B)

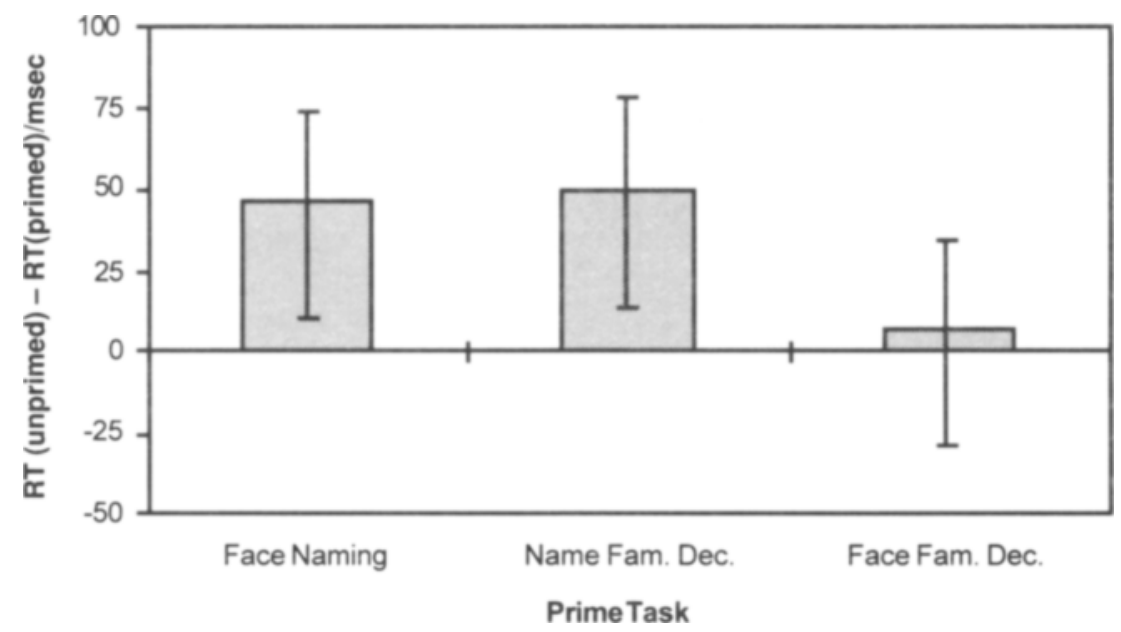

Figure 2. Results of Experiment 1. In panel A, the mean reaction time (RT) to accept famous names as familiar in the test phase is plotted as a function of priming condition and prime task. The "plus" error bars indicate the $95 \%$ confidence interval for the betweensubjects factor from the subjects analysis. (This confidence interval is applicable only to the effect of prime task.) The "minus" error bars indicate the $95 \%$ confidence interval for the within-items factors from the items analysis. (This confidence interval is applicable to both factors.) In panel $B$, the facilitation of $R T$ in the test phase due to repetition priming is plotted as the difference between RT to unprimed items and primed items. The "plus" error bars indicate the $95 \%$ confidence interval for the difference between means for the within-subjects factor of priming from the subjects analysis. The "minus" error bars indicate the same $95 \%$ confidence interval from the items analysis. Confidence intervals have been calculated using the procedure described by Loftus and Masson (1994).

by a significant interaction (reported below) and is entirely attributable to faster RTs to primed items in the face naming task.

The main effect of priming was significant $\left[F_{1}(1,57)=\right.$ $18.15, M S_{\mathrm{e}}=35,776.53, p<.001 ; F_{2}(1,29)=14.97, M S_{\mathrm{e}}$ $=4,125.09, p<.001]$. Mean RTs were 731 and $766 \mathrm{msec}$ to primed and unprimed items, respectively.

The interaction between the factors of prime task and priming was significant in the items analysis $\left[F_{2}(2,58)=\right.$ $\left.4.00, M S_{\mathrm{e}}=3,279.88, p<.05\right]$ and approached significance in the subjects analysis $\left[F_{1}(2,57)=2.87, M S_{\mathrm{e}}=\right.$
$5,647.43, p=.065]$. Analysis of simple main effects revealed a significant effect of priming following the face naming task $\left[F_{1}(1,57)=10.78, M S_{\mathrm{e}}=1,971.17, p<\right.$ $\left..005 ; F_{2}(1,29)=10.14, M S_{\mathrm{e}}=3,809.00, p<.005\right]$ and following the name familiarity decision task $\left[F_{1}(1,57)=\right.$ $12.83, M S_{\mathrm{e}}=1,971.17, p<.001 ; F_{2}(1,29)=14.97$, $M S_{\mathrm{e}}=4,125.09, p<.001$ ], but no effect of priming from the face familiarity decision task $\left(F_{1}<1 ; F_{2}<1\right)$.

In order to assess whether the effect of priming following the face naming task was equivalent to that of the priming observed following the name familiarity deci- 
sion task, further two-way analyses were carried out that included only data from these two tasks. These analyses showed that there was no interaction between the effect of priming and prime task $\left(F_{1}<1 ; F_{2}<1\right)$. Therefore, it can be concluded that the effect of priming following face naming was equivalent to the effect of priming found when name familiarity decision tasks were carried out in both the prime and the test phase.

The mean RT of correct decisions to unfamiliar names presented in the test phase was $965 \mathrm{msec}(S D=238 \mathrm{msec})$ for subjects who named faces in the prime phase; $797 \mathrm{msec}$ $(S D=131 \mathrm{msec})$ for subjects who made familiarity decisions to names in the prime phase, and $926 \mathrm{msec}(S D=$ $200 \mathrm{msec}$ ) for subjects who made familiarity decisions to faces presented in the prime phase.

\section{Discussion}

The predictions derived from the Valentine et al. (1996) framework were supported by the results of Experiment 1 . Naming a famous face provided as much facilitation of a subsequent familiarity decision to the celebrity's name as did a prior name familiarity decision. This result is consistent with strengthening of the PIN-lemma link forming the basis of the observed repetition priming. Furthermore, if the priming task required face recognition, but did not require access to the celebrity's name, no reliable effect of repetition priming was found. Thus access to the name during the prime task is required to obtain a statistically significant effect of repetition priming.

Repetition priming from production to recognition of a person's name is not predicted by previous models of the relationship between name recognition and face naming (Burton et al., 1990; Valentine et al., 1991). The new framework can also account for repetition priming being observed between production and recognition of people's names but not between production and recognition of object names, as reported in the literature.

The effects of repetition priming observed in Experiment 1 cannot be readily explained by other theories of repetition priming. The effects cannot be explained by perceptual fluency (Jacoby \& Dallas, 1981) because as much facilitation was observed when different stimuli were presented in the prime and test phases (faces and names) as when names were presented in both phases.

Any account that predicts that facilitation is influenced by the similarity between the processing tasks carried out in the prime and test phases cannot account for the data (e.g., transfer-appropriate training, Blaxton, 1989; Roediger \& Blaxton, 1987; Roediger, Weldon, \& Challis, 1989). Contrary to such accounts, the effect of priming observed when the tasks carried out in the prime and test phases were different was equivalent to the magnitude of priming observed when the tasks were identical. The prime task that did not produce a reliable effect of repetition priming (face familiarity decision) involved the same decision as the test phase (name familiarity decision), although the stimulus differed.
It could be argued that the facilitation due to repetition resulted from a strategy of response learning. Subjects might have learned that repetitions detected between the prime and test phase were associated with a "yes" response. However, this hypothesis predicts that repetition priming would have been observed in all three priming conditions.

It would be possible to argue that the priming effect was a result of excluding from the analysis items that had elicited an error during the prime phase. This may have eliminated potentially slow responses to the less familiar items from the primed condition but not from the unprimed condition. This account is perfectly plausible but cannot explain the pattern of results observed. It cannot explain why priming was not observed following a face familiarity decision task. The difference in the error rate to primed and unprimed items was greater following face familiarity decisions ( 1.35 vs. 0.40 errors, respectively) than it was following name familiarity decisions ( 1.15 vs. 0.85 errors, respectively). Therefore, this explanation would tend to predict a greater effect of priming from face familiarity decision than from name familiarity decision. In fact, priming was greater following the name familiarity decision.

In conclusion, the results of Experiment 1 are interpreted as strong empirical support for the framework shown in Figure 1.

\section{EXPERIMENT 2}

A further prediction derived from the Valentine et al. (1996) framework is that repetition priming of name familiarity decisions to people's names should cross input modality. That is, having heard a familiar name during a prime phase should prime a familiarity decision to a visually presented name to the same extent as having seen the name during the prime phase. The prediction arises because it is assumed that name familiarity decisions are based on the level of activation of the PIN. The link from the semantic lexicon to the PIN is utilized regardless of the input modality. Therefore, if the strength of this link is increased by a recent presentation of a name (in either modality), repetition priming will be observed.

Previous models of face and name processing do not address the issue of whether repetition priming of name recognition would be modality specific because they have considered only recognition of visual names (Burton et al., 1990; Valentine et al., 1991). These models could easily be extended to allow auditory input of names. The way in which the models are extended would determine the prediction that would be derived.

If it is assumed that name recognition (or input) units are modality specific, and therefore that recognition of heard names is mediated by a set of recognition units separate from those serving visual recognition, reduced or no cross-modality repetition priming would be predicted. If it is assumed that repetition priming is mediated only 
by strengthening of a link between modality-specific name recognition units and the PIN, no repetition priming would be predicted. Reduced repetition priming would be predicted if it is assumed that, in part, repetition priming of the test task is supported by strengthening of links between the PIN and semantic information units. This source of repetition priming would be observed only if processing in both the prime and test task included access to identity-specific semantic information.

However, if it is assumed that name recognition (or input) units are common to both auditory and visual recognition of names, the models would predict crossmodality that is equivalent to within-modality priming. Essentially, in this case the models would predict crossmodality priming for the same reason as the framework in Figure 1. However, these models could not predict the priming of name recognition by name production, as found in Experiment 1.

The prediction of cross-modality priming of equivalent extent to within-modality priming for people's names contrasts with the prediction that would be derived for word recognition. If it is assumed that words can be identified on the basis of activity of a unit in the semantic lexicon, there should be no transfer of repetition priming across modality. If, however, the task required during the test phase requires access to the semantic system and the meaning of the word was activated during the priming event, strengthening of the links between the lemma and units in the semantic system might support a repetition priming effect. Therefore, the prediction depends on the extent of semantic processing required to complete the test task, assuming that the semantic system was activated by the prime.

The literature contains a range of cross-modality effects of repetition that are broadly consistent with this view. Experimenters who have used measures of identification accuracy combined with degraded stimulus presentation (auditory presentation in noise or brief exposures of visual stimuli) have found little or no transfer of repetition effects across modality. Morton (1979) reported that auditory presentation of a word does not prime later visual recognition, but he did find significant priming of identification of auditory words presented in a background of noise from visual presentation of the word. However, there was less facilitation from visually presented words than from auditory presentation. Ellis (1982) found that identification accuracy of auditory words presented in noise was facilitated by a prior semantic classification of auditory words but found no facilitation if the prime word was presented visually. Clarke and Morton (1983) found very little transfer from hearing a word in the prime phase to subsequent visual identification. Weldon (1991) found significant priming of identification of a briefly exposed visual word from hearing the word, but the degree of facilitation was significantly less than that observed if subjects read the word during the prime phase. Jacoby and Dallas (1981; Experiment 6) found significant facilitation of accuracy of visual iden- tification of briefly exposed words $(35 \mathrm{msec})$ from prior study of visual words but no facilitation from prior study of auditory presentation of words.

Kirsner and Smith (1974) and Kirsner, Milech, and Standen (1983) found that auditory presentation of primes produced significant priming of visual lexical decisions, but the priming effect was significantly smaller than that obtained from visual presentation of primes. Kirsner et al. interpreted their results in terms of two loci of repetition priming: a modality-specific component that reflects facilitation of word identification and a modality-free component that is associated with access to semantic representations. The framework shown in Figure 1 is entirely consistent with this interpretation.

Hunt and Toth (1990) and Weldon (1991) found significant facilitation of a visual word fragment completion task from auditory presentation of primes, but visual presentation of the priming stimuli produced significantly greater facilitation. Graf, Shimamura, and Squire (1985) found that cross-modality priming of a visual wordstem completion task showed a significant effect, but one that was significantly smaller than the effect of withinmodality priming. Bassili, Smith, and MacLeod (1989) extended this finding to include within- and cross-modality priming of both visual word-stem completion and an auditory analogue of the task. For both modalities of the test task, priming from cross-modality primes was significant but significantly less than the effect of withinmodality primes.

To summarize, perceptual identification tasks in which the perceptual information is severely degraded - for example, by very brief exposure of visual stimuli or presentation of auditory stimuli in noise-show little or no cross-modality repetition priming. Lexical decision, word fragment completion, and word-stem completion do show some facilitation from cross-modality primes. This pattern of results is consistent with the view that a semantic processing component to the test task is necessary for cross-modality priming to occur. Note that none of the studies cited have shown equivalent effects of repetition priming from cross-modality and within-modality primes. Therefore, our prediction that cross-modality priming of name familiarity decisions would be equivalent to withinmodality priming stands against a considerable body of empirical evidence from word recognition.

Cross-modality and within-modality repetition priming effects in word recognition and name recognition were compared in Experiment 2. The experimental design incorporated three features to make the comparison between word recognition and name recognition as close as possible. First, the name familiarity decision task was selected to be analogous to the lexical decision task (cf. Bruce's, 1983, comparison between face familiarity decisions and lexical decisions). Second, almost all of the surnames used in the name familiarity decision task were also English words that were employed as items in the lexical decision task. Therefore, the data were derived from essentially the same items serving as words or as surnames. Third, 
all aspects of the design were as similar as possible between the two tasks (e.g., number of stimuli, proportion of repeated items, etc.).

\section{Method}

Subjects. Sixty-four volunteers took part in the experiment.

Stimuli. The experimental stimuli for the name familiarity decision task consisted of names of celebrities whose surnames were English words. (One of the names used required a change of spelling Woolf-Wolf). Two sets of 15 critical items were constructed. Names of 35 other celebrities and 80 unfamiliar names were selected. The name stimuli included were either the surname of a celebrity or a surname that occurred in a database of surnames derived from the telephone directory (Moore \& Valentine, 1993). One of the experimenters selected celebrities names judged to be the most familiar to students ( $21 \mathrm{TV}$ personalities, 20 film stars, 6 politicians, 4 sports personalities, 13 pop stars, and 1 author). Stimuli for the lexical decision task consisted of two sets of 15 critical items (the words forming the surnames of the critical stimuli for the name familiarity decision task), and 35 other English words, and 80 pronounceable nonwords (formed by altering one or two letters in the word stimuli). All of the words occurred as surnames in the database. In addition, different stimuli were selected for 10 practice trials for each task in both the prime and test phases. Half the practice items were words or famous names and half were nonwords or unfamiliar names. All of the stimuli used for the experimental trials are listed in Appendix B.

Apparatus. In the tasks that required visual presentation, the stimuli were presented on a PC screen. The subjects' responses were logged by using keypresses on the keyboard. The experiment was programmed using Micro Experimental Laboratory software (Schneider, 1988). RT was recorded with millisecond accuracy. For the auditory presentation of the prime tasks, stimuli were presented via headphones from a cassette tape recorder. The subject made a response by pressing one of two buttons on a hand-held response box. An LED indicator showed which button had been pressed so that accuracy of response could be recorded manually.

Design. The experiment consisted of two phases, a prime phase and a test phase. All subjects carried out the same task during the prime phase and the test phase (either name familiarity decision or lexical decision). The test task was presented visually to all subjects. The experiment had a mixed design with three factors - prime task modality (visual vs. auditory), the task carried out (name familiarity vs. lexical decision), and priming (primed vs. unprimed items). Each subject took part in one of a combination of prime phase modality (auditory or visual) and task. Each combination was carried out by 16 subjects. Therefore, prime task modality and task were between-subjects factors. The effect of priming was a withinsubjects factor. There were two sets of 15 critical items. One set was included in both the prime and the test phases. Responses to these items formed the data from primed items. The other set of $15 \mathrm{criti}$ cal items appeared only in the test phase. Responses to these items formed the data from unprimed items. The assignment of items to the primed and unprimed conditions was counterbalanced across subjects for each combination of prime phase modality and task.

All subjects assigned to a specific task took part in an identical test phase. They made either familiarity decisions to names (first and surnames) or lexical decisions to words, presented on a PC screen. Half of the items required a positive response (famous names or words) and half required a negative response (unfamiliar names or nonwords). The dependent variables were the mean latency of correct responses to critical positive items and the accuracy of responses to these items presented during the test phase.

Procedure. The following details applied to all tasks (four prime task/modality combinations and the test tasks). Each task commenced with 10 practice items. With the exception of the 15 primed items, no other items were repeated between prime and test tasks (including practice items).

In all tasks involving visual presentation, the following details applied. Each trial consisted of a $250-\mathrm{msec}$ tone $500 \mathrm{msec}$ prior to presentation of the stimulus. The subject's response terminated display of the stimulus. Each subject saw a different random order of stimuli.

For the prime tasks that used auditory presentation, the following details applied. Four different orders of stimuli were constructed. Sequence 1 was in random order; Sequence 2 consisted of the second half of Sequence 1 followed by the first half (split-half); Sequences 3 and 4 were Sequences 1 and 2, respectively, presented in reverse order. Four subjects saw the stimuli in each order.

The procedures for the name familiarity decision prime task and the test task were identical. In each trial, a full name was presented. The subjects were instructed to decide whether each name was familiar to them or not. They made their responses by pressing a "yes" or "no" key on the keyboard (or a hand-held response box for the auditory presentation condition). Subjects were instructed to respond as quickly and as accurately as possible. Names of 40 celebrities and 40 unfamiliar names were presented in both the name familiarity decision prime task and the test task.

The procedures for the lexical decision prime task and the test task were identical. The subjects were instructed to decide whether or not each stimulus was an English word. They made their responses by pressing a "yes" or "no" key on the keyboard (or handheld response box for the auditory presentation condition). Subjects were instructed to respond as quickly and as accurately as possible. Forty words and 40 nonwords were presented in both the lexical decision prime task and the test task.

\section{Results}

Responses to the 15 critical primed and unprimed items made during the test phase were subjected to analysis. A response to a primed item was included in the analyses only if the correct response was given in both the prime phase and the test phase. Errors (in the prime and/or test phase) were made to $7.1 \%$ of stimuli. The accuracy of responses is given in Table 2 as a function of prime modal-

Table 2

Mean Number of Errors Per Subject in Experiment 2 (Maximum $=15$ ) as a Function of Task, Prime Modality, and Prime Condition

\begin{tabular}{|c|c|c|c|c|c|c|c|c|c|c|c|c|c|c|c|c|c|c|c|c|}
\hline \multirow{3}{*}{$\begin{array}{c}\text { Prime } \\
\text { Modality }\end{array}$} & \multicolumn{8}{|c|}{ Name Familiarity Decision } & \multicolumn{8}{|c|}{ Lexical Decision } & \multirow{2}{*}{\multicolumn{4}{|c|}{ Mean }} \\
\hline & \multicolumn{4}{|c|}{ Auditory } & \multicolumn{4}{|c|}{ Visual } & \multicolumn{4}{|c|}{ Auditory } & \multicolumn{4}{|c|}{ Visual } & & & & \\
\hline & $M$ & $\%$ & $S D$ & $\%$ & $M$ & $\%$ & $S D$ & $\%$ & $M$ & $\%$ & $S D$ & $\%$ & $M$ & $\%$ & $S D$ & $\%$ & $M$ & $\%$ & $S D$ & $\%$ \\
\hline Primed & 1.75 & 11.67 & 2.05 & 13.67 & 1.44 & 9.60 & 1.86 & 12.40 & 1.31 & 8.73 & 1.66 & 11.07 & 0.81 & 5.40 & 1.51 & 10.07 & 1.33 & 8.87 & 1.77 & 11.80 \\
\hline Unprimed & 0.53 & 3.53 & 0.89 & 5.93 & 1.44 & 9.60 & 1.36 & 9.07 & 0.75 & 5.00 & 0.77 & 5.13 & 0.56 & 3.73 & 0.89 & 5.93 & 0.83 & 5.53 & 1.05 & 7.00 \\
\hline Mean & 1.16 & 7.73 & 1.67 & 11.13 & 1.44 & 9.60 & 1.61 & 10.73 & 1.03 & 6.87 & 1.31 & 8.73 & 0.69 & 4.60 & 1.23 & 8.20 & & & & \\
\hline
\end{tabular}

Note-Error rates for primed stimuli include trials on which an error was made in either the prime phase or the test phase. 
ity, task, and priming condition. As in Experiment 1, the higher error rate to primed items than to unprimed items occurred because a correct response had to be made on two occasions (prime and test phase) for the response to be counted as correct, whereas unprimed items were presented in the test phase only. No further analysis of accuracy data was carried out.

Mean RTs of correct responses to critical items in the test phase are plotted in Figure 3. In panel A, the mean for each experimental condition is plotted. The effect of priming is illustrated in panel $\mathrm{B}$, in which the difference be- tween RTs to unprimed and primed items is plotted. The error bars indicate the appropriate $95 \%$ confidence intervals from the subjects and items analyses reported below. The data illustrated in panel A were subjected to a $2 \times 2$ $\times 2$ slit-plot ANOVA with repeated measures on the priming factor, taking subjects as the random factor (identified below with the suffix 1), and to an ANOVA with repeated measures on priming and prime modality, taking items as the random factor (identified below by the suffix 2 ).

The main effect of task was significant $\left[F_{1}(1,60)=\right.$ $11.11, M S_{\mathrm{e}}=61,592.24, p=.001 ; F_{2}(1,58)=87.73$,

(A)

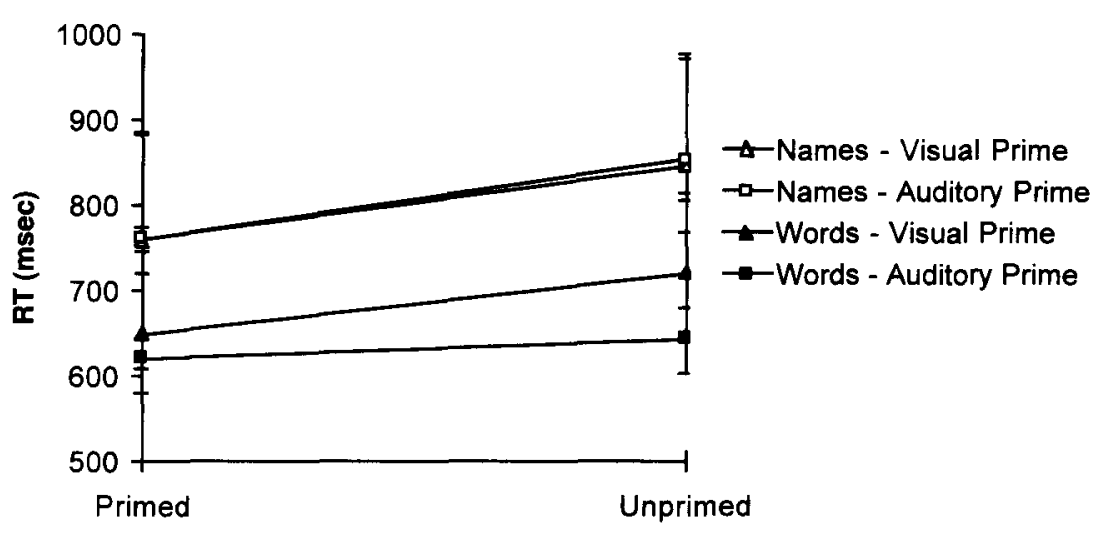

(B)

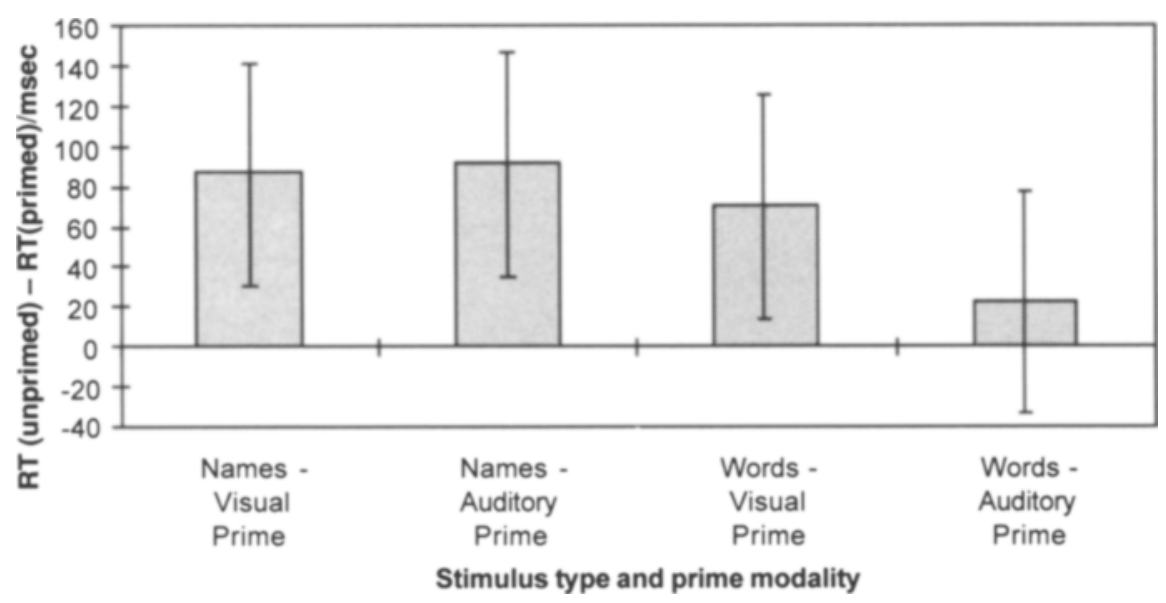

Figure 3. Results of Experiment 2. In panel A, the mean reaction time (RT) of correct positive responses in the test phase is plotted as a function of the modality of the prime task and the type of stimulus in the prime and test phases. The "plus" error bars indicate the $95 \%$ confidence interval for the between-subjects factor from the subjects analysis. (This confidence interval is applicable only to the effect of modality of the prime task and type of stimulus.) The "minus" error bars indicate the $95 \%$ confidence interval for the within-items factors from the items analysis. (This confidence interval is applicable to all factors.) In panel $B$, the facilitation of $R T$ in the test phase due to repetition priming is plotted as the difference between RT to unprimed items and primed items. The "plus" error bars indicate the $95 \%$ confidence interval for the difference between means for the within-subjects factor of priming from the subjects analysis. The "minus" error bars indicate the same $\mathbf{9 5 \%}$ confidence interval from the items analysis. Confidence intervals have been calculated using the procedure described by Loftus and Masson (1994). 
$\left.M S_{\mathrm{e}}=17,311.55, p<.001\right]$. Mean RT for name familiarity decisions ( $805 \mathrm{msec}$ ) was slower than the mean RT for lexical decisions $(659 \mathrm{msec})$. The main effect of priming was significant $\left[F_{1}(1,60)=24.38, M S_{\mathrm{e}}=\right.$ $6,032.97, p<.001 ; F_{2}(1,58)=22.48, M S_{\mathrm{e}}=10,868.76$, $p<.001]$. The mean RT to primed items $(698 \mathrm{msec})$ was faster than the mean RT to unprimed items $(766 \mathrm{msec})$.

The main effect of modality was significant in the items analysis only $\left[F_{2}(1,58)=5.28, M S_{\mathrm{e}}=6,864.47, p<.05\right.$; $\left.F_{1}<1\right]$. This effect was modified by a significant interaction between task and modality in the items analysis $\left[F_{2}(1,58)=9.99, M S_{\mathrm{e}}=6,864.47, p<.005 ; F_{1}<1\right]$. Analysis of simple main effects showed a significant effect of prime modality in the lexical decision task $\left[F_{2}(1,58)=14.88, M S_{\mathrm{e}}=6,864.47, p<.001\right]$ but not in the name familiarity decision task $\left(F_{2}<1\right)$. Lexical decisions preceded by an auditory prime task were faster than lexical decisions preceded by a visual prime task. The effect was not reliable in the subjects analysis (in which modality was a between-subjects factor). It has no clear theoretical interpretation and could be due to differences in the speed of responding between the different groups of subjects who took part in each combination of prime modality and task. No other effects were statistically significant.

The hypothesis predicted a three-way interaction between the effects of priming, prime modality, and task. The predicted interaction was explored further in separate two-way ANOVAs for each task. Analyses of the name familiarity decision task showed no interaction between the effects of priming and prime modality $\left(F_{1}\right.$ and $\left.F_{2}<1\right)$. Analyses of the lexical decision task showed a significant interaction in the items analysis only $\left[F_{1}(1,30)=2.40\right.$, $M S_{\mathrm{e}}=3,873.33, p=.13 ; F_{2}(1,29)=5.05, M S_{\mathrm{e}}=$ $2,863.96, p<.05]$. Analyses of simple main effects showed a significant effect of priming when the prime task and test task both used visual presentation $\left[F_{1}(1,30)=10.36\right.$, $M S_{\mathrm{e}}=3,878.33, p<.005 ; F_{2}(1,29)=9.63, M S_{\mathrm{e}}=$ $8,131.21 ; p<.005]$. When the prime task was presented in the auditory modality, there was no significant priming of lexical decisions $\left[F_{1}(1,30)=1.06, M S_{\mathrm{e}}=3,873.33\right.$, $\left.p=.31 ; F_{2}(1,29)=2.34, M S_{\mathrm{e}}=5,155.01, p=.14\right]$.

The mean RT of correct responses to nonwords included in the test task for subjects who carried out the lexical decision task was $848 \mathrm{msec}(S D=226 \mathrm{msec})$. The mean RT for correct responses to unfamiliar names included in the test task for subjects who carried out the name familiarity decision task was $1,005 \mathrm{msec}(S D=266 \mathrm{msec})$.

\section{Discussion}

Experiment 2 was designed to test the prediction, derived from the framework shown in Figure 1, that repetition priming of name familiarity decisions would cross stimulus modality. The results are very clear. Making a familiarity decision to a name heard during the prime phase produced just as much facilitation of a subsequent familiarity decision to a visually presented name as ob- served when the familiarity decision during the prime phase was made to a visual name. The experimental design allowed a close comparison between name familiarity decision and lexical decision because the surnames used in the familiarity decision task occurred as words in a lexical decision task. In this case, analysis of simple main effects showed that repetition priming was observed when the priming stimulus was presented in the same modality as the test item (visually), but the effect of repetition did not reach statistical significance if the prime phase consisted of lexical decisions to auditory stimuli. The results are not consistent with the transfer-appropriate training hypothesis. This hypothesis would have predicted maximum priming when the processing demands of the prime and test tasks were most similar. According to this view, same-modality primes would have produced more priming than different-modality primes for both lexical decisions and name familiarity decisions. Neither can the results be explained by the hypothesis of perceptual fluency (Jacoby \& Dallas, 1981). Presentation of a different stimulus in the different-modality condition of the name familiarity decision task did not reduce the facilitation due to repetition compared with a same-modality prime. Under these conditions, there is no mechanism for perceptual fluency to provide facilitation because a stimulus with entirely different physical properties is presented in the prime and test phases.

It might be argued that exclusion of primed items that elicited errors in the prime phase removed items from the analysis that could potentially have produced the slower responses in the primed condition. However, examination of Table 2 shows that this effect alone cannot account for the pattern of results. The difference in the error rate to primed and unprimed items was greatest in the name familiarity decision primed by auditory presentation ( 1.75 vs. 0.56 errors, respectively), and yet the effect of priming was equivalent to that observed when there was no difference in the error rate to primed and unprimed items (name familiarity decision primed by visual presentation). Furthermore, when lexical decisions were primed by auditory presentation, the difference in error rate to primed and unprimed items was the second highest observed in any of the experimental conditions ( 1.31 vs. 0.75 ), and yet this was the only condition in which no reliable effect of priming was observed.

\section{GENERAL DISCUSSION}

Valentine et al. (1996) proposed that a semantic lexicon is common to the production and recognition of names, including processing of people's names. Two predictions follow from this organization that distinguish the framework from previous models of face and name processing. First, it was predicted that production of a person's name in response to seeing his/her face would prime a familiarity decision to his/her written name. Experiment 1 supported this prediction. It was noted that, consistent 
with the literature, the framework does not predict a similar effect of object naming. Naming an object does not prime recognition of the object name. In this way, the relationship between production and recognition of people's names is different from the relationship found for object names.

Second, a semantic lexicon that is common to recognition of written language and speech gives rise to the prediction that repetition priming of familiarity decisions to people's names will be no less when the prime and test stimuli are presented in different modalities than the effect would be if they are presented in the same modality. This prediction does not apply to word recognition: There would be a greater effect of repetition priming of lexical decisions when both the prime and the test stimuli are presented in the same modality than when they are presented in different modalities. Experiment 2 supported these predictions. Thus, the relationship between recognition of spoken and written forms of people's names is different from the relationship found for common names.

The results show remarkably clear evidence that processing of people's names is carried out by a cognitive architecture that has a significantly different organization from processing of common names. The aspect of processing people's names that makes it different is that recognition of a person's name (in speech or in writing) and production of a person's name require access to a token marker in memory, labeled as a "person identity node" in the framework (as in models of face recognition). It is believed that the token marker distinguishes processing of all classes of proper names from common names (see Valentine et al., 1996).

The exact definition of a proper name has proved problematic for psychologists and philosophers. For example, proper names are often thought of as denoting an individual entity. So are trade names (e.g., Volkswagen Golf) proper names? Intuitively, the answer may appear to be "yes," but the name Volkswagen Golf may have millions of referents. Some philosophers of language suggest that proper names are pure referring expressions that have no sense. However, some information can be conveyed by people's names even if the referent (i.e., the person who holds that name) is completely unfamiliar. For example, it would be possible to guess that Yoko Ono is Japanese, or that Margaret Thatcher is female even if these specific names had never been encountered before. In another domain of proper names, one would expect London Bridge to refer to a bridge and Buckingham Palace to be a palace. One may not be assured of being correct in such judgments, but there is a very high probability of being correct.

Although the definition of a proper name can be problematic, the experiments reported here provide an empirical method for establishing whether a name is a proper name. The results that are characteristic of people's names are attributed to the role of a token marker in memory. Therefore, if recognition and production of a specific name is mediated by a token marker, it will show repeti- tion priming from production to recognition and repetition priming of recognition that is as great across modality as it is within modality. Since this empirical method can be used to determine whether processing is mediated by a token marker, it can establish whether a particular stimulus or stimulus class is a proper name. Therefore, we can make the strong prediction that geographical names (cities, rivers, etc.) should show the same pattern of results as that observed in the experiments reported here for people's names. Trade names would be a less clear case.

In addition to the implications for proper name processing, the results reported here have important implications for models of word recognition, speech perception, speech production, and the relationships among these models. Our results provide empirical support for Roelofs's (1992) model of speech production, which included a semantic lexicon common to word recognition and speech production. Models of word recognition fail to distinguish a semantic lexicon from nonlexical semantic representations, on the one hand, and from a phonological lexicon, on the other. Previous authors have concluded that it is not possible to say whether a single lexicon is used for both speech perception and speech production on the basis of empirical evidence alone (Ellis \& Young, 1988; Monsell, 1987; Shallice, 1988). However, incorporating separate semantic and phonological lexicons into models of speech perception, speech production, and word recognition-which have a semantic lexicon common to input and output processing - provides a promising means of resolving theoretical difficulties and providing a single theoretical basis for processing models that have developed largely in isolation.

\section{REFERENCES}

Bassili, J. N., SMith, M. C., \& MacLeon, C. M. (1989). Auditory and visual word-stem completion: Separating data-driven and conceptuallydriven processes. Quarterly Journal of Experimental Psychology, 41A, 439-453.

BLAXTON, T. A. (1989). Investigating dissociations among memory measures: Support for a transfer-appropriate processing framework. Journal of Experimental Psychology: Learning, Memory, \& Cognition, 15, 657-668.

Brédart, S., \& Valentine, T. (1992). From Monroe to Moreau. An analysis of face naming errors. Cognition, 45, 187-223.

Brédart, S., Valentine, T., Calder, A., \& Gassi, L. (1995). An interactive activation model of face naming. Quarterly Journal of Experimental Psychology, 48A, 466-486.

BRUCE, V. (1983). Recognizing faces. Philosophical Transactions of the Royal Society of London: Series B, 302, 423-436.

Bruce, V., \& Young, A. (1986). Understanding face recognition. British Journal of Psychology, 77, 305-327.

Burton, A. M., Bruce, V., \& Johnston, R. A. (1990). Understanding face recognition with an interactive activation model. British Journal of Psychology, 81, 361-380

ClaRke, R., \& MoRTON, J. (1983). Cross modality facilitation in tachistoscopic word recognition. Quarterly Journal of Experimental Psychology, 35A, 79-96.

DELL, G. S. (1986). A spreading activation theory of retrieval in sentence production. Psychological Review, 93, 283-321.

ELLIS, A. W. (1982). Modality-specific repetition priming of auditory word recognition. Current Psychological Research, 2, 123-128. 
Ellis, A. W., \& Young, A. W. (1988). Human cognitive neuropsychology. Hove, U.K.: Erlbaum.

GARRETT, M. F. (1975). The analysis of sentence production. In G. H. Bower (Ed.), The psychology of learning and motivation (Vol. 9, pp. 133-175). New York: Academic Press.

GARRETT, M. F. (1980). Levels of processing in sentence production. In B. Butterworth (Ed.), Language production: Vol. 1. Speech and talk (pp. 177-220). London: Academic Press.

Graf, P., Shimamura, A. P., \& Seuire, L. R. (1985). Priming across modality and priming across category levels: Extending the domain of preserved function in amnesia. Journal of Experimental Psychology: Learning, Memory, \& Cognition, 11, 386-396.

HaY, D. C., \& Young, A. W. (1982). The human face. In A. W. Ellis (Ed.), Normality and pathology in cognitive functions (pp. 173-202). London: Academic Press.

HUNT, R. R., \& ToTH, J. P. (1990). Perceptual identification, fragment completion, and free recall: Concepts and data. Journal of Experimental Psychology: Learning, Memory, \& Cognition, 16, 282-290.

JACOBY, L. L., \& DaLLAS, M. (1981). On the relationship between autobiographical memory and perceptual learning. Journal of Experimental Psychology: General, 110, 306-340.

Kirsner, K., Milech, D., \& Standen, P. (1983). Common and modalityspecific processes in the mental lexicon. Memory \& Cognition, 11, 621-630.

KIRSNER, K., \& SMITH, M. C. (1974). Modality effects in word identification. Memory \& Cognition, 2, 637-640.

LEVELT, W. J. M. (1989). Speaking: From intention to articulation. Cambridge, MA: MIT Press.

Loftus, G. R., \& Masson, M. E. J. (1994). Using confidence intervals in within-subject designs. Psychonomic Bulletin \& Review, 1, 476-490.

MonselL, S. (1987). On the relation between lexical input and output pathways for speech. In A. Allport, D. Mackay, W. Prinz, \& E. Scheerer (Ed.), Language perception and production: Relationships between listening, speaking, reading and writing (pp. 273-311). London: Academic Press.

Monsell, S., Matthews, G. H., \& Miller, D. C. (1992). Repetition of lexicalization across languages: A further test of the locus of priming. Quarterly Journal of Experimental Psychology, 44A, 763-783.

MOORE, V., \& VALENTINE, T. (1993). Names count: An assessment of surname frequencies in North West England (Unpublished database).

MORTON, J. (1979). Facilitation in word recognition: Experiments causing change in the logogen model. In P. A. Kolers, M. Wrolstad, \& H. Bouma (Ed.), Processing of visible language (pp. 259-268). New York: Plenum.

RoEdiger, H. L., III, \& BLAXTON, T. A. (1987). Effects of varying modality, surface features, and retention interval on priming in wordfragment completion. Memory \& Cognition, 15, 379-388.

Roediger, H. L., III, Weldon, M. S., \& Challis, B. A. (1989). Explaining dissociations between implicit and explicit measures of retention: A processing account. In H. L. Roediger III \& F. I. M. Craik (Eds.), Varieties of memory and consciousness: Essays in honour of Endel Tulving (pp. 3-41). Hillsdale, NJ: Erlbaum

RoELOFs, A. (1992). A spreading-activation theory of lemma retrieval in speaking. Cognition, 42, 107-142.

Scarborough, D. L., Gerard, L., \& Cortese, C. (1979). Accessing lexical memory: The transfer of word repetition effects across task and modality. Memory \& Cognition, 7, 3-12.

SCHNEIDER, W. (1988). Micro Experimental Laboratory. An integrated system for IBM-PC compatibles. Behavior Research Methods, Instruments, \& Computers, 20, 206-217.

SeIDEnBerg, M. S. (1988). Cognitive neuropsychology and language: The state of the art. Cognitive Neuropsychology, 5, 403-426.

SHALliCE, T. (1988). From neuropsychology to mental structure. Cambridge: Cambridge University Press.

VAlENTINE, T., BRÉDART, S., LAWSON, R., \& WARD, G. (1991). What's in a name? Access to information from people's names. European Journal of Cognitive Psychology, 3, 147-176.

VAlentine, T., BRennen, T., \& BRÉDART, S. (1996). The cognitive psy- chology of proper names: On the importance of being Ernest. London Routledge.

VitKovitch, M., \& Humphreys, G. W. (1991). Perseverant responding in speeded naming to pictures: It's in the links. Journal of Experimental Psychology: Learning, Memory, \& Cognition, 17, 664-680.

WELDON, M. S. (1991). Mechanisms underlying priming on perceptual tests. Journal of Experimental Psychology: Learning, Memory, \& Cognition, 17, 526-541.

WinNick, W. A., \& DANIEL, S. A. (1970). Two kinds of response priming in tachistoscopic recognition. Journal of Experimental Psychology, 84, 74-81.

\section{NOTE}

1. Monsell (1987) did not consider the role of a semantic lexicon that is separate from both nonlexical semantic representations and a phonological lexicon. If it is assumed that Monsell's "conceptual/functional attributes," which he described as representing semantic properties, syntactic class, and usage conventions, is equivalent to a semantic lexicon, our model is a case of his Model 3. Monsell argued that the balance of the evidence favors this model. See Valentine et al. (1996, pp. 175-176) for further discussion.

\section{APPENDIX A Stimuli Used in Experiment 1}

\section{Critical (Celebrity) Items}

Set 1: Les Dawson, Jack Nicholson, Paul Hogan, Mel Gibson, Johnathon Ross, Jimmy Saville, Elizabeth Taylor, Peter Cushing, Rowen Atkinson, Marilyn Monroe, Bruce Forsyth, Woody Allen, Barbara Windsor, Esther Rantzen, Michael Aspel.

Set 2: Michael Crawford, David Bellamy, Ben Elton, Charlie Chaplin, Ken Dodd, Michael Hesaltine, Meryl Streep, Clint Eastwood, Clive Anderson, Jenny Agutter, Burt Reynolds, Sue Lawly, Joanna Lumley, Anthony Hopkins, Michael Palin.

\section{Prime Phase}

Face familiarity decision condition: Stimuli included 40 unfamiliar faces, 15 celebrity faces from either Set 1 or Set 2 above (counterbalanced across subjects), and the following 25 celebrities' faces:

Ruby Wax, Judy Garland, Cilla Black, Bob Hope, James Hunt, Freddie Mercury, Wayne Sleep, Jeffrey Archer, David Steel, Charles Dance, George Bush, Victoria Wood, Tony Hancock, Dave Allen, Bill Clinton, Michael Jackson, Tom Cruise, Paddy Ashdown, Boris Becker, Sean Connery, John McEnroe, Sue Pollard, Steve McQueen, Jason Donovan, Eric Clapton.

Face naming condition: Stimuli included 15 celebrity faces from either Set 1 or Set 2 (counterbalanced across subjects), the 25 celebrities' faces included in the face familiarity decision condition, and the following 35 additional celebrities' faces:

Steve Cram, David Bowie, Phil Collins, Charles Bronson, Michae Douglas, Arthur Scargill, Liza Minelli, Dennis Healey, Robert Maxwell, Bob Geldof, Robin Williams, Phillip Schofield, Michael Parkinson, Clive James, Cliff Richard, Geoff Boycott, Leslie Crowther, Gary Linaker, Sylvester Stallone, Roger Moore, Michelle Pfeiffer, Derek Jameson, Jimmy Carter, River Phoenix, Cristopher Leigh, Richard Branson, Bill Beaumont, Dean Martin, John Cleese, Paul Daniels, Anna Ford, Dawn French, Aneka Rice, John Major, Benny Hill.

Name familiarity decision condition: The stimuli were the printed names of 15 celebrity faces from either Set 1 or Set 2 (counterbalanced across subjects), the names of the 25 celebri- 
ties included in the face familiarity decision condition, and the following 40 unfamiliar names:

John Pilgrim, Tim Riddle, Keith Knight, Robert Twig, Mark Wise, Victoria Twill, Benny Proud, Peter Cash, Susan Shade, Denise Black, Sterling Monks, Jenny Raw, Tim Tring, Raquel Wander, Brook Sear, Oliver Park, June Robe, Janet Simpler, Lee North, Gregory Yard, Tom Rudder, Virginia Short, Margaret Wilder, Clair Root, Peter Rosewood, Freddie Plover, Dawn Slater, Virginia Younger, Lloyd Marsh, River Thresh, James Green, Amanda Edge, Peter Lord, June Player, Jeremy Stammer, Jodie Sell, John Price, Buddy Peacock, Paul Longhorn, Jerry Brown.

\section{Test Phase}

All subjects took part in the same test phase. Stimuli were the printed names of the 30 celebrities included in Set 1 and Set 2 and the following 10 celebrities' names:

Betty Boo, Frank Brough, Billy Idol, Judy Dench, Julia McKenzie, Vera Lynn, Julie Walters, Virginia Wade, Dustin Hoffman, Frank Sinatra.

Also included were the following 40 unfamiliar names:

Adam Amberton, Jeffrey Bendet, Roger Burrows, Simon Chard, Cilla Flay, Betty Morrison, Frank Walker, George Joss, Julie Taylor, Jimmy Burton, Phil Lawson, Peter Millhouse, Tommy Forden, Noel Kanock, Steve Mellows, Kevin Gilbert, Tom Tuft, Robin Wilson, James Sower, Francis Tiller, Adam Plover, Carrie Storey, Harrison Quin, Jodie Tiffin, Michael Mote, Dawn Kotch, David Lapwing, Steven Milton, Clark Stoops, Judy Wright, Gary Pleat, Jerry Topper, Tony Mileson, Nigel Ratty, Buddy Mutter, Bob Netting, Dennis Royle, Billy Skimming, Jeremy Ping, Oliver Thompson.

\section{APPENDIX B Stimuli Used in Experiment 2}

\section{Critical Items: Names}

Set 1: Jeffrey Archer, Cilla Black, George Burns, Tommy Cooper, James Dean, Adam Faith, Brian Blessed, Judy Garland, Billy Idol, Oliver Reed, Stan Laurel, Sterling Moss, Barbara Castle, Tina Turner, Virginia Woolf.

Set 2: Simon Bates, Buddy Holly, Bob Hope, George Bush, Quentin Crisp, Carrie Fisher, Samantha Fox, Mae West, Dawn French, Peter Cook, Jeremy Irons, John Major, Margaret Thatcher, Jimmy Carter, Jody Foster.

\section{Prime Phase}

Name familiarity decision: The stimuli consisted of 15 celebrities' names from either Set 1 or Set 2 (counterbalanced across subjects) and the following 25 "filler" famous names:

Roger Bannister, Gary Glitter, Tony Hatch, Hayley Mills, Tim Rice, Sid Vicious, Bobby Brown, Victoria Wood, Michael Fish, Benny Hill, Lloyd Bridges, Brook Shields, Paul Young, Freddie Mercury, Ruby Wax, Clark Gable, Gregory Peck, River Phoenix, Robin Day, David Frost, Tom Cruise, Jerry Hall, Robert Plant, Rock Hudson, Johnathon King.
Also included were the 40 unfamiliar names included in the name familiarity decision task used in the prime phase of Experiment 1 (listed in Appendix A).

\section{Test Phase}

Name familiarity decision: The stimuli consisted of the celebrity names included in Sets 1 and 2 and the following 10 "filler" celebrity names:

Oliver Hardy, Wayne Sleep, Stephany Powers, Aneka Rice, Christopher Dean, Juliet Mills, James Hunt, Russell Grant, Gracey Fields, Ann Diamond.

Also included were the 40 unfamiliar names listed below:

Adam Amber, Jeffrey Bend, Roger Burrows, Simon Chard, Cilla Flay, Betty Grey, Frank Hawk, George Joss, Julie Kitchen, Jimmy Marshall, Pat Law, Peter Millhouse, Kettle, Noel Luck, Steve Mellows, Kevin Gill, Tom Sly, Robin South, James Sower, Francis Tiller, Adam Stokes, Carrie Storey, Harrison Swan, Jodie Tack, Michae Long, Dawn Thrush, David Thriller, Steven Tribe, Clark Stoops, Judy Wright, Gary Street, Gerry Towered, Tony Mote, Nigel Muff, Buddy Mutter, Bob Netting, Dennis Nice, Billy Oats, Jeremy Pagen, Oliver Cram.

\section{Critical Items: Words}

Set 1: archer, black, burns, cooper, dean, faith, blessed, garland, idol, reed, laurel, moss, castle, turner, wolf.

Set 2: bates, holly, hope, bush, crisp, fisher, fox, west, french, cook, irons, major, thatcher, carter, foster.

\section{Prime Phase}

Lexical decision: The stimuli consisted of 15 words from either Set 1 or Set 2 (counterbalanced across subjects) and the following 25 "filler" words:

banister, glitter, hatch, mills, rice, vicious, brown, wood, fish, hill, bridges, shields, young, mercury, wax, gable, peck, phoenix, day, frost, cruise, hall, plant, rock, king.

Also included were the 40 nonwords listed below:

polgrem, raddlo, knught, twag, wesh, twell, praud, cesh, shede, rebe, munks, bleck, riw, thrang, wender, seir, pirk, sempler, narth, yird, ridder, shart, walder, roet, rosawood, pliver, sleter, yoenger, mirsh, thrish, grean, edga, lird, pleyer, stemmer, sall, prace, parcock, longhirn, brewn.

\section{Test Phase}

Lexical decision: The stimuli consisted of the words included in Sets 1 and 2 and the following 10 "filler" words:

hardy, sleep, powers, rice, dean, mills, hunt, grant, fields, diamond.

Also included were the 40 nonwords listed below:

ambar, bund, birrows, chird, floy, griy, howk, jiss, kotchen, boll, mallhuose, kattle, leck, mullows, gell, sude, seuth, suwer, tuller, stukes, stirkey, swen, teck, limg, thrish, thraller, trabe, stoaps, wraght, streit, tawered, mete, meff, metter, natting, noce, oets, pegen, crim. 